\title{
Geriatric falls in the context of a hospital fall prevention program: delirium, low body mass index, and other risk factors
}

\section{Katarzyna Mazur \\ Krzysztof Wilczyński Jan Szewieczek}

Department of Geriatrics, School of Health Sciences in Katowice, Medical University of Silesia, Katowice, Poland
Correspondence: Jan Szewieczek Department of Geriatrics, GCM, ul Ziolowa 45/47, 40-635 Katowice, Poland

Tel +48 323598239

Fax +48 322059483

Email jszewieczek@sum.edu.pl
This article was published in the following Dove Press journal:

Clinical Interventions in Aging

14 September 2016

Number of times this article has been viewed

Background: Inpatient geriatric falls are a frequent complication of hospital care that results in significant morbidity and mortality.

Objective: Evaluate factors associated with falls in geriatric inpatients after implementation of the fall prevention program.

Methods: Prospective observational study comprised of 788 consecutive patients aged $79.5 \pm 7.6$ years $(\bar{\chi} \pm$ standard deviation) ( $66 \%$ women and $34 \%$ men) admitted to the subacute geriatric ward. Comprehensive geriatric assessment (including Mini-Mental State Examination, Barthel Index of Activities of Daily Living, and modified Get-up and Go Test) was performed. Confusion Assessment Method was used for diagnosis of delirium. Patients were categorized into low, moderate, or high fall risk groups after clinical and functional assessment.

Results: About $15.9 \%, 21.1 \%$, and $63.1 \%$ of participants were classified into low, moderate, and high fall risk groups, respectively. Twenty-seven falls were recorded in 26 patients. Increased fall probability was associated with age $\geq 76$ years $(P<0.001)$, body mass index (BMI) $<23.5$ $(P=0.007)$, Mini-Mental State Examination $<20(P=0.004)$, Barthel Index $<65(P=0.002)$, hemoglobin $<7.69 \mathrm{mmol} / \mathrm{L}(P=0.017)$, serum protein $<70 \mathrm{~g} / \mathrm{L}(P=0.008)$, albumin $<32 \mathrm{~g} / \mathrm{L}$ $(P=0.001)$, and calcium level $<2.27 \mathrm{mmol} / \mathrm{L}$. Four independent factors associated with fall risk were included in the multivariate logistic regression model: delirium (odds ratio $[\mathrm{OR}]=7.33$; $95 \%$ confidence interval $[95 \% \mathrm{CI}]=2.76-19.49 ; P<0.001)$, history of falls $(\mathrm{OR}=2.55 ; 95 \%$ $\mathrm{CI}=1.05-6.19 ; P=0.039)$, age $(\mathrm{OR}=1.14 ; 95 \% \mathrm{CI}=1.05-1.23 ; P=0.001)$, and $\mathrm{BMI}(\mathrm{OR}=0.91$; $95 \% \mathrm{CI}=0.83-0.99 ; P=0.034)$.

Conclusion: Delirium, history of falls, and advanced age seem to be the primary risk factors for geriatric falls in the context of a hospital fall prevention program. Higher BMI appears to be associated with protection against inpatient geriatric falls.

Keywords: falls, geriatric inpatients, comprehensive geriatric assessment, delirium, body mass index

\section{Introduction}

Inpatient geriatric falls are a frequent complication of hospital care that results in significant morbidity and mortality, including serious injuries, prolonged hospitalization, increased hospital financial liability, decreased quality of life, and increased risk for placement in nursing homes. ${ }^{1-6}$ Prevention strategies and interventions that have been implemented at the hospital and hospital ward level have been shown by others to reduce the number of fall incidents. ${ }^{7,8}$ Multiple fall risk factors have been identified in community-dwelling elderly, among them specific medical conditions, ${ }^{9-12}$ balance and gait disorders, history of falls, visual impairment, advanced age, female sex, 
Table I Components of the fall prevention program implemented in the Department of Geriatrics at University Hospital Number 7 SUM, Katowice, Poland

I) Components of the fall prevention program

I) Comprehensive geriatric assessment with fall risk evaluation at admission and the documentation and analysis of all patient fall data irrespective of fall complications

2) Patient and caregiver education (including ward layout and instruction on use of the nurse call button, safe footwear, orthopedic equipment as well as the necessity of requesting staff assistance during ambulation)

3) Addressing vision and hearing impairment where possible

4) Medication review and reduction where possible, especially minimization of psychoactive drugs or those with anticholinergic activity. In addition, adjustments are made to avoid overly aggressive antihypertensive, antiarrhythmic, and antihyperglycemic treatment

5) Adequate hydration and feeding

6) Treatment of chief complaint and comorbidities

7) Pain relief

8) Individualized rehabilitation, including physiotherapy, for maintenance of mobility

9) Matching orthopedic devices with patients when necessary along with instruction on how to properly use the equipment

10) Patient monitoring and surveillance adjusted to individual mental and physical status

II) Symptoms and signs indicating high fall risk (any of the following conditions)

Recurrent falls or syncope reported by the patient or their caregiver, recent fall or syncope as reason for hospitalization, substantial balance or gait disorders, fear of falling, severe weakness, serious mental disorders (disorientation and agitation), advanced uncorrected vision or hearing impairment, symptomatic orthostatic hypotension, positive Romberg or other neurological signs of impaired balance, modified Get-up and Go Test $^{24}$ score below 6 points, or Tinetti POMA ${ }^{25}$ score below 19 points

III) Symptoms and signs indicating moderate fall risk (any of the following conditions)

Fall or syncope in the last 12 months reported by the patient or their caregiver, mild balance or gait disorders, moderate weakness, mild mental disorders, moderate vision or hearing impairment, asymptomatic orthostatic hypotension, minor neurological signs of potential balance impairment, modified Get-up and Go Test ${ }^{24}$ score 6-7 points, or Tinetti POMA ${ }^{25}$ score 19-23 points

Abbreviation: POMA, Performance-Oriented Mobility Assessment.

polypharmacy, pain, cognitive decline, and environmental factors. ${ }^{13,14}$ Certain medications have also been shown to be associated with increased fall risk in community-based elderly, including antiarrhythmics, nonselective $\beta$-blockers, benzodiazepines, and antidepressants. ${ }^{15}$ Specifically in hospitalized patients, alterations in consciousness, inattention, ${ }^{16}$ confusion, ${ }^{17}$ anemia, osteoporosis, and a history of falls ${ }^{3}$ as well as specific medications, including benzodiazepines, haloperidol, tricyclic antidepressants, ${ }^{17}$ zolpidem, and calcium channel antagonists, ${ }^{18}$ were identified as fall risk factors. The STRATIFY scale was found to be the best tool for assessing the risk of falls for hospitalized acutely ill adults. ${ }^{19}$ However, no screening tool has shown sufficient prognostic accuracy to be recommended for predicting falls among newly admitted acute care hospital patients aged 65 years or older. ${ }^{20,21}$

In 2013, a standard operational program for fall and delirium prevention was implemented in the Department of Geriatrics at University Hospital Number 7 SUM, Katowice, Poland, a subacute geriatric ward at a multiprofile university hospital. For the purposes of the program, fall was defined as a sudden, uncontrolled body transition caused by loss of body balance control or body support instability. In addition to inpatient geriatric fall prevention strategies described by others, ${ }^{1}$ this program classifies patients at admission according to three levels of geriatric fall risk: low, moderate, and high (Table 1). The assessment includes clinical and functional evaluation made by the department team. Initial fall risk classification is modified if patient status changes significantly during hospitalization. On the basis of a comprehensive geriatric assessment, an individualized multifactorial approach to reduce patient fall risk is applied. Patient ambulation is restricted based on patient fall risk assessment: moderate-risk patients are instructed to request staff assistance before ambulating between dusk and dawn, while high fall risk patients are instructed to request staff assistance before ambulating at all times. These restrictions are accompanied by an individualized rehabilitation program for each patient, directed at early mobilization and maintenance of mobility. Patients with cognitive impairment are provided with increased nursing surveillance. The program requires the documentation and analysis of all patient fall data irrespective of fall complications. The study was designed to analyze geriatric falls in hospitalized patients after implementation of a fall prevention program.

\section{Patients and methods \\ Participants}

This prospective observational study comprised of 788 consecutive patients aged $79.5 \pm 7.6$ years $(\bar{\chi} \pm$ standard deviation) within a range of $60-100$ years, among whom $66 \%$ were women and $34 \%$ were men. Participants were admitted to the 
Department of Geriatrics at University Hospital Number 7 SUM Uppersilesian Medical Center in Katowice, Poland, a subacute geriatric ward at a multiprofile university hospital, between June 2013 and June 2014.

\section{Measurements}

Patients were evaluated by taking comprehensive general history (including fall history and balance disorders) and by performing a physical examination (postural balance and gait assessment), geriatric functional assessment, blood work (Table 2), electrocardiogram, abdominal ultrasound, and chest X-ray. BIS_cr equation ${ }^{22}$ was used to estimate glomerular filtration rate. This method is recommended in very elderly persons if cystatin $\mathrm{C}$ is not available. ${ }^{23}$ Modified Get-up and Go Test $^{24}$ (scored from 0 to 10 with lower values suggesting increased ambulatory disability) was used to evaluate patient fall risk. The test consists of five exercises: 1) rise from a hard chair with backrest, 2) stand for 5 seconds, 3) walk a distance of $3 \mathrm{~m}$ at normal speed, 4) execute a $180^{\circ}$ turn and return to the chair, and 5) sit down in the chair. Each of the tasks is scored either 2 points (normal, confident, self-reliant performance), 1 point (mildly to moderately abnormal performance - use of orthopedic devices or any deviation from a confident, normal, but self-reliant, performance), or 0 points (severely abnormal - need for staff assistance or inability of self-reliant performance of the exercise). Tinetti Performance-Oriented Mobility Assessment ${ }^{25}$ was also applied in a limited number of cases to assess risk of falls (scored from 0 to 28 with lower values indicating higher fall risk). Mini-Mental State Examination (MMSE) ${ }^{26}$ was used to assess global cognitive performance. Geriatric Depression Scale-Short Form was used to screen for depression. ${ }^{27}$ Barthel Index of Activities of Daily Living (Barthel Index) ${ }^{28}$ and Lawton Instrumental Activities of Daily Living Scale (IADL) ${ }^{29}$ were used to determine functional status. MMSE scores range from 0 to 30, Barthel Index from 0 to 100, and IADL from 9 to 27; higher scores indicate better functional status. Geriatric Depression Scale-Short Form scores range from 0 to 15 , with higher scores indicating higher depression probability. Confusion Assessment Method for diagnosis of delirium ${ }^{30}$ was applied. Dementia was diagnosed according to recommendations from the National Institute on Aging-Alzheimer's Association. ${ }^{31}$ Pain intensity was assessed with the Visual Analog Scale $^{32,33}$ scored from 0 to 10 , or with Doloplus- 2 scale ${ }^{34,35}$ based on the behavioralobservational method and scored from 0 to 30 points (with higher scores indicating more severe pain) in patients who were unable to report pain intensity because of cognitive impairment. To harmonize both pain scales, Doloplus-2 values were divided by a factor of 3 and pain intensity was scored from 0 to 10 in each patient. Body mass index (BMI) was calculated in all subjects. On the basis of clinical and functional assessment, patients were categorized into low, moderate, and high fall risk groups (Table 1).

\section{Data collection}

Data was collected by three research nurses and entered into predefined forms.

\section{Statistical analysis}

Data were analyzed using STATISTICA version 10 (StatSoft, Inc., Tulsa, OK, USA). Chi-square test, $V$-square test, and Fisher's exact test were used for categorical variables, and the nonparametric Mann-Whitney $U$-test for quantitative variables was used to compare patients who experienced a fall during hospitalization with those who did not. Probability density analysis was used to calculate fall probability with regard to hospitalization day and time. Multivariate binary logistic regression was performed to assess factors predictive of falls. Variables were adjusted for clinical, functional, and laboratory factors. Multivariate analysis with backward elimination included variables that yielded $P$-values of 0.1 or lower in the initial univariate analysis (Table 3). The Kaplan-Meier method was used to estimate probability of fall-free hospitalization in subgroups of patients with respect to select variables, while differences between these subgroups were assessed with the Wilcoxon-Gehan method. Variables were tested to define the value corresponding with the lowest $P$ level. $P$-values $<0.05$ were considered statistically significant.

\section{Ethics}

The study protocol was registered with the Bioethical Committee of the Medical University of Silesia in Katowice, Poland. The committee determined that "the study is characterized by record review and in the context of law is not a medical experiment and does not require assessment by the bioethical committee" (Letter KNW/0022/KB/78/I/13). On the basis of this decision, study participant written informed consent was not required for our study nor was separate patient consent required for our statistical analysis or research since patient data are not disclosed outside internal hospital ward staff.

\section{Results}

On the basis of assessment at admission, 15.9\%, 21.1\%, and $63.1 \%$ of study participants were classified into low, moderate, 
Table 2 Demographic, clinical, and functional differences between patients who experienced falls during hospitalization (group F) as compared with patients who did not (group C)

\begin{tabular}{|c|c|c|c|}
\hline \multirow[t]{2}{*}{ Variable } & $\begin{array}{l}\text { Group F } \\
(n=26)\end{array}$ & $\begin{array}{l}\text { Group C } \\
(n=762)\end{array}$ & \multirow{2}{*}{$\begin{array}{l}\text { Group F vs } \\
\text { group C } \\
\text { P-value }\end{array}$} \\
\hline & \multicolumn{2}{|c|}{ Mean \pm SD or percentage } & \\
\hline Age, years & $86.0 \pm 5.0$ & $79.3 \pm 7.6$ & $<0.001$ \\
\hline Sex, percentage of females & 66.5 & 53.8 & 0.179 \\
\hline Hypertension, \% & 73.1 & 76.1 & 0.721 \\
\hline Diabetes mellitus, \% & 34.6 & 29.7 & 0.587 \\
\hline Myocardial infarction in anamnesis, \% & 11.5 & 11.8 & 0.789 \\
\hline Congestive heart failure, $\%$ & 34.6 & 23.9 & 0.210 \\
\hline Stroke in anamnesis, \% & 7.69 & 12.8 & 0.632 \\
\hline Peripheral artery disease, $\%$ & 7.69 & 6.96 & 0.805 \\
\hline Parkinson's disease, \% & 0.00 & 7.34 & 0.296 \\
\hline Dementia in anamnesis, \% & 46.2 & 21.5 & 0.003 \\
\hline Delirium in anamnesis, \% & 7.69 & 2.63 & 0.350 \\
\hline Cancer in anamnesis, \% & 15.4 & 11.3 & 0.739 \\
\hline Falls in anamnesis, \% & 61.5 & 35.2 & 0.006 \\
\hline Fall-related injuries in anamnesis, \% & 23.1 & 8.27 & 0.009 \\
\hline Behavioral disorders in anamnesis, \% & 26.9 & 11.3 & 0.015 \\
\hline Pressure ulcers, \% & 0.00 & 3.15 & 0.735 \\
\hline Urinary incontinence, \% & 46.2 & 41.3 & 0.624 \\
\hline Bladder catheterization, \% & 3.85 & 8.01 & 0.686 \\
\hline Number of used medications & $5.15 \pm 2.38$ & $5.06 \pm 2.59$ & 0.892 \\
\hline Neuroleptic treatment before admission, \% & 30.8 & 15.5 & 0.037 \\
\hline High fall risk, \% & 76.9 & 62.6 & 0.496 \\
\hline $\mathrm{BMI}, \mathrm{kg} / \mathrm{m}^{2}$ & $24.3 \pm 3.7$ & $27.5 \pm 5.8$ & 0.003 \\
\hline Heart rate, beats per minute & $72.1 \pm 10.0$ & $71.8 \pm 12.4$ & 0.529 \\
\hline Systolic blood pressure, $\mathrm{mmHg}$ & $131.9 \pm 24.0$ & $134.5 \pm 19.4$ & 0.427 \\
\hline Diastolic blood pressure, $\mathrm{mmHg}$ & $74.8 \pm 10.4$ & $76.8 \pm 10.1$ & 0.533 \\
\hline CAM, points & $1.12 \pm 1.73$ & $0.16 \pm 0.74$ & 0.037 \\
\hline MMSE score & $20.7 \pm 6.6$ & $22.6 \pm 7.9$ & 0.040 \\
\hline Barthel Index & $57.9 \pm 26.3$ & $70.2 \pm 29.2$ & 0.011 \\
\hline Lawton IADL & $16.0 \pm 6.0$ & $18.5 \pm 6.4$ & 0.038 \\
\hline Modified Get-up and Go Test & $3.65 \pm 2.61$ & $4.47 \pm 2.77$ & 0.094 \\
\hline Hemoglobin, mmol/L & $7.30 \pm 1.34$ & $7.76 \pm 1.14$ & 0.052 \\
\hline White blood cells, G/L & $7.93 \pm 3.23$ & $7.60 \pm 3.75$ & 0.361 \\
\hline Total protein, g/L & $66.2 \pm 6.2$ & $70.4 \pm 7.4$ & 0.003 \\
\hline Albumin, $g / L$ & $32.0 \pm 5.8$ & $35.2 \pm 6.1$ & 0.008 \\
\hline Glucose, $\mathrm{mmol} / \mathrm{L}$ & $5.84 \pm 2.04$ & $6.27 \pm 2.11$ & 0.108 \\
\hline Bilirubin, $\mu \mathrm{mol} / \mathrm{L}$ & $11.10 \pm 5.90$ & $11.23 \pm 8.82$ & 0.830 \\
\hline Alanine transaminase, $\mathrm{nmol} / \mathrm{L} / \mathrm{s}$ & $604 \pm I, 438$ & $332 \pm 317$ & 0.286 \\
\hline Creatinine, $\mu \mathrm{mol} / \mathrm{L}$ & $90.0 \pm 27.0$ & $92.3 \pm 56.3$ & 0.398 \\
\hline Estimated GFR using BIS_creatinine & $53.6 \pm 18.4$ & $62.1 \pm 24.8$ & 0.041 \\
\hline equation, $\mathrm{mL} / \mathrm{min} / 1.73 \mathrm{~m}^{2}$ & & & \\
\hline Thyrotropin, mIU/L & $1.91 \pm 1.39$ & $2.57 \pm 6.38$ & 0.817 \\
\hline Vitamin $B_{12}, \mathrm{pmol} / \mathrm{L}$ & $264.9 \pm 152.0$ & $310.7 \pm 202.2$ & 0.304 \\
\hline Total cholesterol, mmol/L & $4.00 \pm 0.89$ & $4.53 \pm 1.17$ & 0.095 \\
\hline LDL-cholesterol, mmol/L & $2.3 I \pm 0.74$ & $2.64 \pm 0.98$ & 0.196 \\
\hline HDL-cholesterol, mmol/L & $1.19 \pm 0.49$ & $1.36 \pm 0.43$ & 0.201 \\
\hline Triglycerides, mmol/L & $1.26 \pm 0.56$ & $1.16 \pm 0.47$ & 0.475 \\
\hline C-reactive protein, $\mathrm{mg} / \mathrm{L}$ & $23.2 \pm 29.2$ & $23.0 \pm 47.0$ & 0.126 \\
\hline Sodium, mmol/L & $137.8 \pm 5.0$ & $139.2 \pm 4.1$ & 0.189 \\
\hline Potassium, $\mathrm{mmol} / \mathrm{L}$ & $4.12 \pm 0.73$ & $4.18 \pm 0.54$ & 0.551 \\
\hline Calcium, mmol/L & $2.26 \pm 0.12$ & $2.33 \pm 0.17$ & 0.009 \\
\hline Delirium incident during hospitalization, \% & 30.8 & 3.81 & $<0.001$ \\
\hline Neuroleptic use during hospitalization, \% & 42.3 & 14.6 & $<0.001$ \\
\hline
\end{tabular}

Abbreviations: BMI, body mass index; BIS, Berlin Initiative Study; CAM, Confusion Assessment Method; GFR, glomerular filtration rate; HDL, high-density lipoprotein; IADL, Instrumental Activities of Daily Living Scale; LDL, low-density lipoprotein; MMSE, Mini-Mental State Examination; SD, standard deviation. 
Table 3 Variables that yield $P$-values of 0.1 or lower in the initial univariate logistic regression analysis of factors predictive of falls

\begin{tabular}{|c|c|c|c|}
\hline Variable & $P$-value & OR & $95 \% \mathrm{Cl}$ \\
\hline \multicolumn{4}{|l|}{ Quantitative variables } \\
\hline Highest recorded CAM value, points & $<0.001$ & 1.85 & $1.45-2.36$ \\
\hline Age & $<0.001$ & 1.15 & $1.08-1.23$ \\
\hline Barthel index at admission, points & 0.038 & 0.99 & $0.98-1.00$ \\
\hline $\begin{array}{l}\text { Estimated GFR using BIS_creatinine } \\
\text { equation, } \mathrm{mL} / \mathrm{min} / 1.73 \mathrm{~m}^{2}\end{array}$ & 0.070 & 0.98 & $0.96-1.00$ \\
\hline Lawton IADL at admission, points & 0.058 & 0.94 & $0.89-1.00$ \\
\hline Serum albumin level, g/L & 0.013 & 0.93 & $0.88-0.99$ \\
\hline Serum total protein level, g/L & 0.005 & 0.93 & $0.89-0.98$ \\
\hline $\mathrm{BMI}, \mathrm{kg} / \mathrm{m}^{2}$ & 0.006 & 0.89 & $0.82-0.97$ \\
\hline Serum total calcium level, $\mathrm{mg} / \mathrm{dL}$ & 0.052 & 0.58 & $0.33-1.01$ \\
\hline \multicolumn{4}{|l|}{ Categorical variables } \\
\hline Delirium occurrence at the ward & $<0.001$ & 9.82 & $3.98-24.22$ \\
\hline Neuroleptic use during hospitalization & $<0.001$ & 4.30 & $1.93-9.61$ \\
\hline History of fall-related trauma & 0.013 & 3.33 & $1.29-8.59$ \\
\hline Dementia & 0.005 & 3.13 & $1.42-6.89$ \\
\hline History of falls & 0.008 & 2.95 & $1.32-6.59$ \\
\hline Behavioral disorders in anamnesis & 0.020 & 2.90 & I.18-7.09 \\
\hline Neuroleptic use before admission & 0.042 & 2.43 & $|.03-5.7|$ \\
\hline
\end{tabular}

Abbreviations: BIS, Berlin Initiative Study; BMI, body mass index; CAM, Confusion Assessment Method; Cl, confidence interval; GFR, glomerular filtration rate; IADL Instrumental Activities of Daily Living Scale; OR, odds ratio.

and high fall risk groups, respectively. Twenty-seven falls were registered in 26 patients; three falls in the low-risk group of 125 patients ( $11.5 \%$ of patients who fell), three falls in the moderate-risk group of 166 patients (11.5\%), and 20 falls in the high-risk group of 497 patients (76.9\%). No fall was complicated by serious injury or decline in functional status. Increased hospital fall activity occurred on day 2 of hospitalization, with day 0 taken as day of admission (Figure 1). We observed a 24-hour biphasic pattern of increased falls with a minor spike between 04:00 and 05:00 and a major spike in the evening, about 21:00 (Figure 2). Among other demographics,

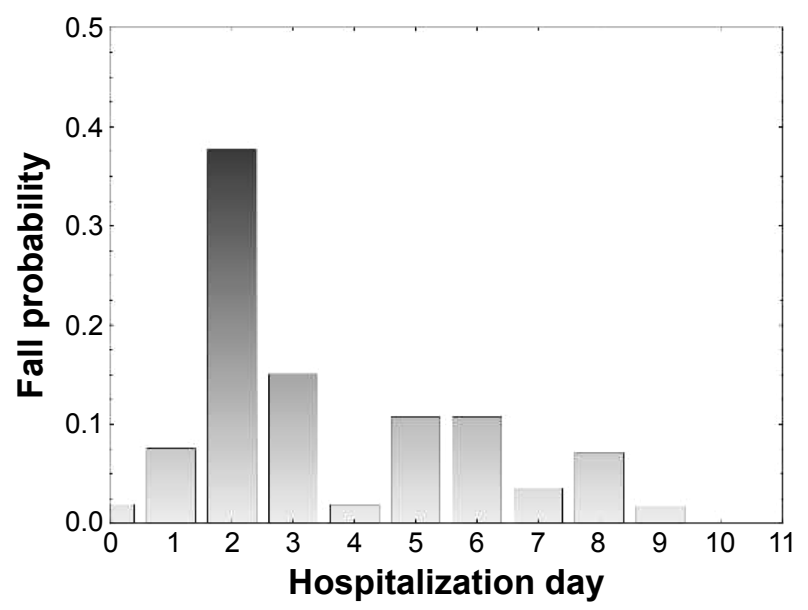

Figure I Fall probability of geriatric inpatients who experienced a fall incident during hospitalization in relation to hospitalization day.

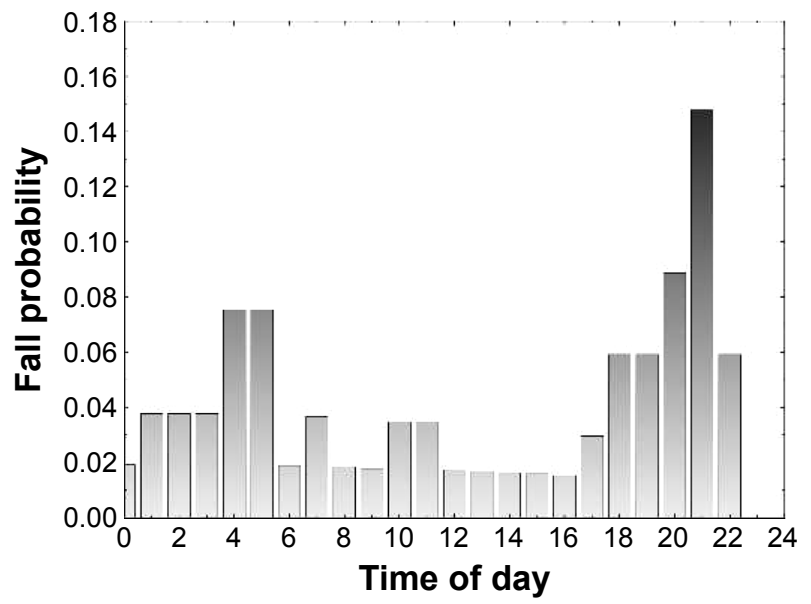

Figure 2 Fall probability of geriatric inpatients who experienced a fall incident during hospitalization in relation to the time of day.

laboratory, and clinical factors, patients with dementia, treated with neuroleptics before and during hospitalization, as well as patients with lower cognitive and functional status tended to be associated with increased falls (Table 2). Increased fall probability was associated with age $\geq 76$ years $(P<0.001)$, BMI $<23.5(P=0.007)$, MMSE $<20(P=0.004)$, and Barthel Index $<65(P=0.002$; Figure $3 \mathrm{~A}-\mathrm{D})$, as well as with hemoglobin level $<7.69 \mathrm{mmol} / \mathrm{L}(P=0.017)$, serum protein level $<70 \mathrm{~g} / \mathrm{L}(P=0.008)$, albumin level $<32 \mathrm{~g} / \mathrm{L}(P=0.001)$, and calcium level $<2.27 \mathrm{mmol} / \mathrm{L}(P=0.001)$ (Figure 4A-D). Four independent factors associated with risk of fall were included in the multivariate logistic regression model: delirium occurrence at the ward (odds ratio $[\mathrm{OR}]=7.33 ; 95 \%$ confidence interval $[\mathrm{CI}]=2.76-19.49 ; P<0.001$ ), history of falls $(\mathrm{OR}=2.55 ; 95 \% \mathrm{CI}=1.05-6.19 ; P=0.039)$, age $(\mathrm{OR}=1.14$; $95 \% \mathrm{CI}=1.05-1.23 ; P=0.001)$, and $\mathrm{BMI}(\mathrm{OR}=0.91 ; 95 \% \mathrm{CI}$ $=0.83-0.99 ; P=0.034)$.

\section{Discussion}

As is the case for many geriatric syndromes, fall prevention in the hospital or health care facility setting requires multifactorial risk assessment and interventions tailored to specific patient needs. ${ }^{36}$ Fall risk factors in the elderly may differ depending on local environmental conditions. Despite numerous studies, no well-defined and highly effective fall prevention program for the elder-care setting has been described. Therefore, it seems reasonable to compare results from different centers. We examined fall incidence and related risk factors in geriatric ward patients after implementation of a staff-developed fall prevention program in 2013. A significant proportion of our patients were identified during screening as being at moderate or high fall risk, which 

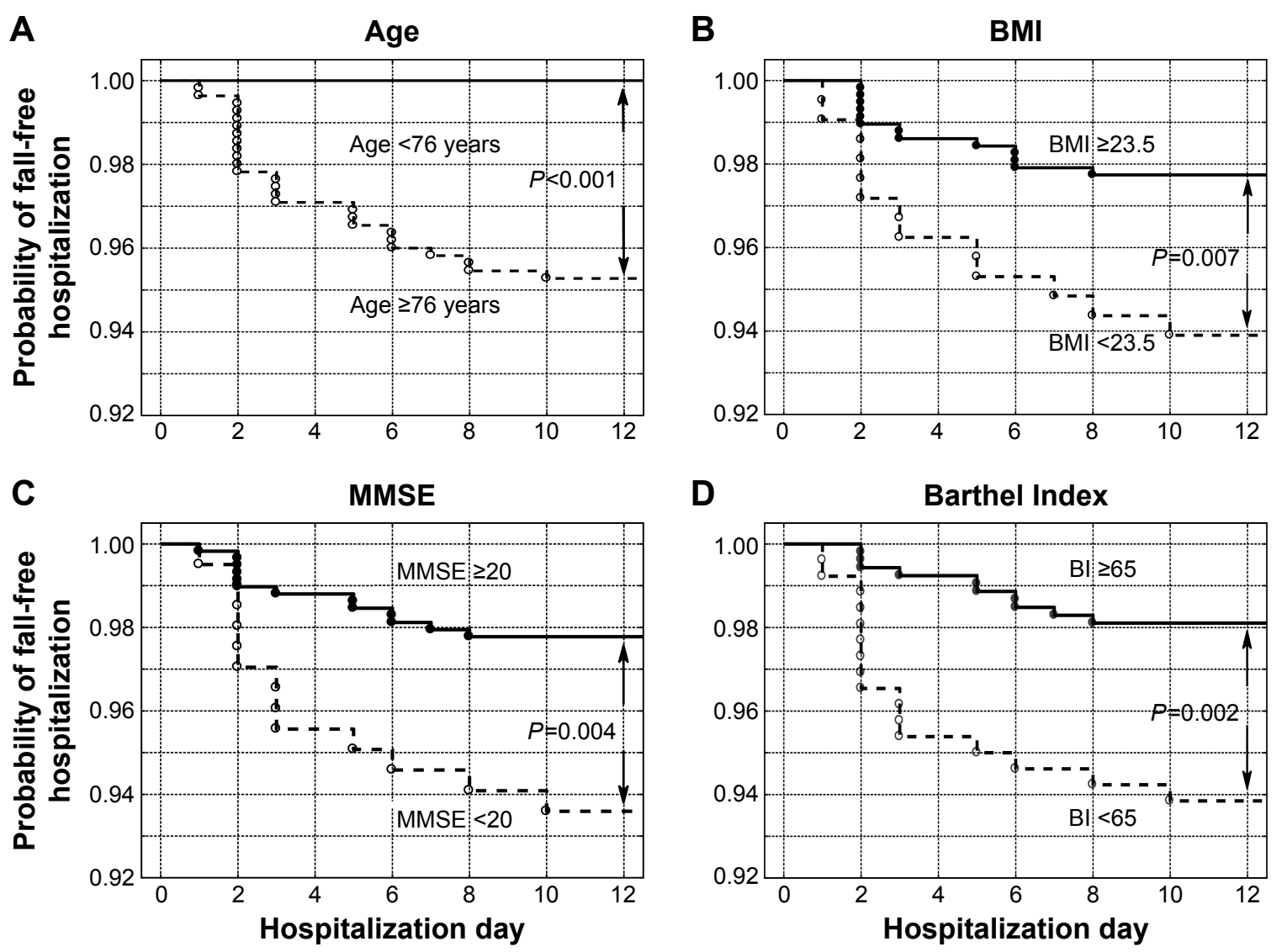

Figure 3 Probability of fall-free hospitalization according to $(\mathbf{A})$ age $<76$ years compared to older age, (B) BMI $\geq 23.5$ compared to lower values, (C) MMSE scores $\geq 20$ compared to lower values, and (D) Barthel Index of Activities of Daily Living $(\mathrm{BI}) \geq 65$ compared to lower values.

Abbreviations: BMI, body mass index; MMSE, Mini-Mental State Examination.

is consistent with other similar studies. ${ }^{20,21}$ This suggests high sensitivity but low specificity and obviates the need for better fall prediction tools for assessing geriatric patients admitted to the acute care hospital wards. Serious injury or decline in functional status was not observed as a consequence of the 27 recorded falls that 26 patients experienced during the study period. Notably, we observed an increased fall probability on the second day of patient hospitalization during evening hours. This observation, of particular practical significance, is most likely multifactorial and complex. Loss of visual perception during periods between dusk and dawn may have a magnified effect in persons with impaired senses, including geriatric patients. This explanation would seem to be supported by studies associating lighting and perceptual cues in older adults with risk of falls. ${ }^{37}$ Evening or nocturnal psychomotor agitation (sundown syndrome) is a common phenomenon in patients with cognitive impairment, which may result in failure to adhere to ambulatory restrictions and result in increased tendency toward falls. ${ }^{38}$ In the literature, data on 24-hour fall patterns in the hospital setting are inconsistent. ${ }^{39}$ Among demographic and clinical characteristics of patients who experienced falls, advanced age, history of falls, dementia, and poor functional state were, as it would be expected from other studies, ${ }^{36}$ factors predictive of falls. Lower BMI appeared to be another risk factor in our study group. Coutinho et $\mathrm{al}^{40}$ showed that $\mathrm{BMI} \leq 20$, cognitive impairment, previous stroke, and lack of urine control were associated with increased incidence of severe fall-related fractures in 250 hospitalized patients matched with 250 community controls. O'Neil et a ${ }^{17}$ found association between low BMI ( $\leq 18.5)$ and increased risk of hospital falls. Decreased body mass may be related to frailty, a syndrome prevalent in geriatric inpatients, ${ }^{41}$ associated with increased fall risk. ${ }^{42}$ Both low and very high BMI are associated with increased prevalence of frailty. ${ }^{43}$ However, some observations indicate that obesity may be protective against falling in community-dwelling older adults. ${ }^{44}$ Delirium appears to be the greatest risk factor for falls in our cohort of inpatients. Delirium-related cognitive deterioration combined with psychomotor agitation acutely impairs both patient compliance and secure mobility. ${ }^{45,46}$ Other studies demonstrated that agitation was associated with falls in 
A

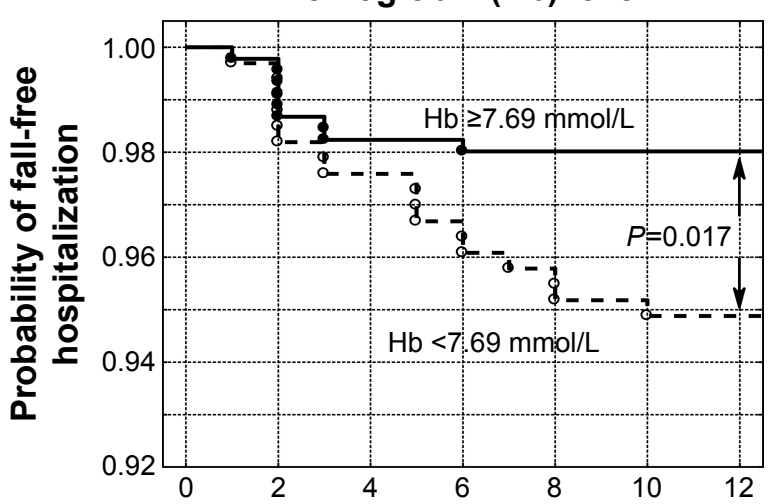

C

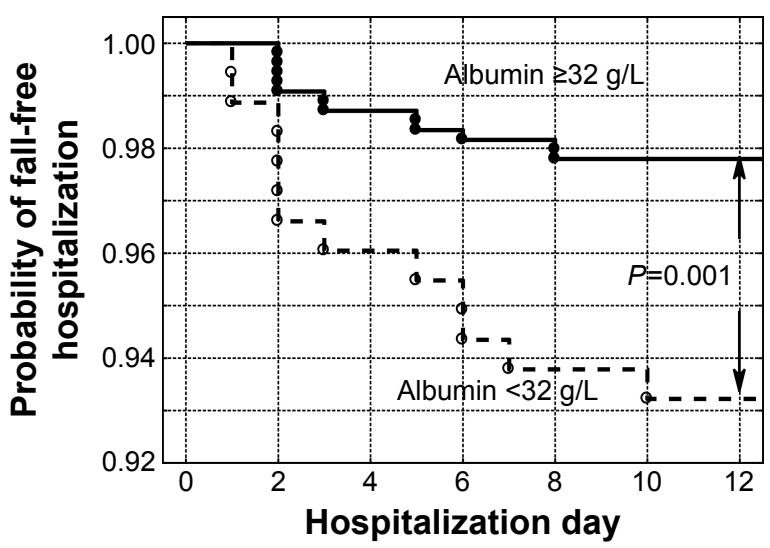

B

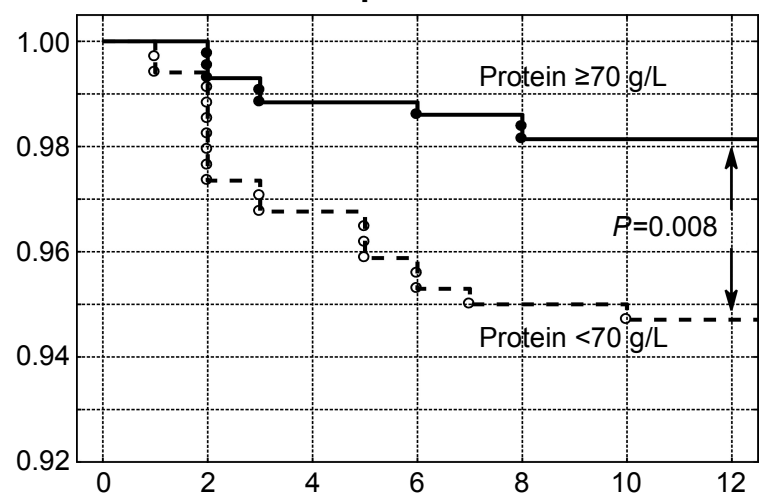

D

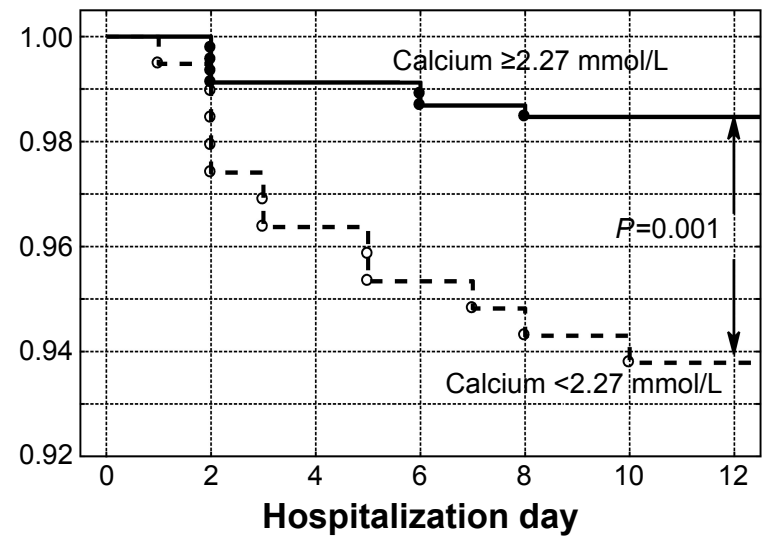

Figure 4 Probability of fall-free hospitalization according to $(\mathbf{A})$ hemoglobin level $\geq 7.69 \mathrm{mmol} / \mathrm{L}$ compared to lower values, $(\mathbf{B})$ serum total protein level $\geq 70$ g/L compared to lower values, $(\mathbf{C})$ serum albumin level $\geq 32 \mathrm{~g} / \mathrm{L}$ compared to lower values, and $(\mathbf{D})$ serum total calcium level $\geq 2.27 \mathrm{mmol} / \mathrm{L}$ compared to lower values.

patients residing in elder-care units. ${ }^{47,48}$ Delirium has also been associated with previous falls both in acute general medicine patients ${ }^{49}$ as well as in geriatric ward patients. ${ }^{50}$ A history of falls has been recognized as predictive of future falls during hospitalization..$^{51}$

Implementation of a geriatric fall prevention program in the hospital setting presents unique challenges for medical professionals. Particular care must be taken to address fall interventions that may also inadvertently complicate comorbid conditions. Specifically, restricting patient-independent ambulation during hospitalization in moderate- and high-risk patients may decrease overall ambulation during hospitalization in these patients and increase the probability of delirium. Additional concerns with restriction of independent ambulation include strain on limited staff time, eliciting or enhancing a fear of falling among a susceptible population, ${ }^{52}$ or even the implication of loss of independence. ${ }^{36} \mathrm{~A}$ critical compensatory intervention in this respect is a comprehensive individualized rehabilitation program directed toward early mobilization and maintenance of mobility for prevention of both falls and their risk factors, including delirium. ${ }^{1,45}$ Given the morbidity and mortality associated with hospital falls, clinicians have been working toward the goal of decreasing hospital falls to the point of "never-events" ${ }^{53}$ In this respect, temporary limits on patient-independent ambulation during hospitalization seem reasonable.

The main limitation of our study was the lack of fall risk comparison before and after program implementation. Our fall prevention program assessed all patients admitted to the ward and documented all patient falls irrespective of fall complications. Since fall data before program implementation were incomplete, we were unable to assess the effectiveness of the program interventions. Nevertheless, it appears that an effective fall prophylaxis program requires implementation of evidence-based as well as common-sense interventions and counseling strategies.

\section{Conclusion}

Delirium, history of falls, and advanced age seem to be the primary risk factors for geriatric falls in the context of a 
hospital fall prevention program. Higher BMI appears to be associated with protection against inpatient geriatric falls.

\section{Funding}

This project was funded by Medical University of Silesia grants to statutory work (contracts KNW-1-029/K/4/0) and graduate student research agreement $(\mathrm{KNW}-2 / 035 / \mathrm{D} / 4 / \mathrm{N})$.

\section{Disclosure}

The authors report no conflicts of interests in this work.

\section{References}

1. Inouye SK, Brown CJ, Tinetti ME. Medicare nonpayment, hospital falls, and unintended consequences. N Engl J Med. 2009;360: 2390-2393.

2. Cameron ID, Gillespie LD, Robertson MC, et al. Interventions for preventing falls in older people in care facilities and hospitals. Cochrane Database Syst Rev. 2012;12:CD005465.

3. al Tehewy MM, Amin GE, Nassar NW. A study of rate and predictors of fall among elderly patients in a university hospital. J Patient Saf. 2015;11:210-214.

4. Anderson DC, Postler TS, Dam TT. Epidemiology of hospital system patient falls: a retrospective analysis. Am J Med Qual. Epub April 8, 2015.

5. Basic D, Hartwell TJ. Falls in hospital and new placement in a nursing home among older people hospitalized with acute illness. Clin Interv Aging. 2015;10:1637-1643.

6. Twibell RS, Siela D, Sproat T, Coers G. Perceptions related to falls and fall prevention among hospitalized adults. Am J Crit Care. 2015;24: e78-e85.

7. Oliver D, Connelly JB, Victor CR, et al. Strategies to prevent falls and fractures in hospitals and care homes and effect of cognitive impairment: systematic review and meta-analyses. BMJ. 2007;334:82.

8. Quigley PA, Barnett SD, Bulat T, Friedman Y. Reducing falls and fallrelated injuries in medical-surgical units: one-year multihospital falls collaborative. J Nurs Care Qual. 2016;31:139-145.

9. Rudzińska M, Bukowczan S, Stożek J, et al. Causes and consequences of falls in Parkinson disease patients in a prospective study. Neurol Neurochir Pol. 2013;47:423-430.

10. Lee K, Pressler SJ, Titler M. Falls in patients with heart failure: a systematic review. J Cardiovasc Nurs. Epub September 29, 2015.

11. Minet LR, Peterson E, von Koch L, Ytterberg C. Occurrence and predictors of falls in people with stroke: six-year prospective study. Stroke. 2015;46:2688-2690.

12. Mamoto $\mathrm{K}$, Inui $\mathrm{K}$, Okano $\mathrm{T}$, et al. Incidence rate of falls and its risk factors in patients with rheumatoid arthritis compared to controls: four years of the TOMORROW study. Mod Rheumatol. Epub May 4, 2016.

13. Ambrose AF, Paul G, Hausdorff JM. Risk factors for falls among older adults: a review of the literature. Maturitas. 2013;75:51-61.

14. Munch T, Harrison SL, Barrett-Connor E, et al. Pain and falls and fractures in community-dwelling older men. Age Ageing. 2015;44:973-979.

15. Ham AC, Swart KM, Enneman AW, et al. Medication-related fall incidents in an older, ambulant population: the B-PROOF study. Drugs Aging. 2014;31:917-927.

16. Doherty K, ArchambaultE, Kelly B, Rudolph JL. Delirium markers in older fallers: a case-control study. Clin Interv Aging. 2014;9:2013-2018.

17. O’Neil CA, Krauss MJ, Bettale J, et al. Medications and patient characteristics associated with falling in the hospital. J Patient Saf. Epub March 16, 2015.

18. Kozono A, Isami K, Shiota K, et al. Relationship of prescribed drugs with the risk of fall in inpatients. Yakugaku Zasshi. 2016;136:769-776.
19. Aranda-Gallardo M, Morales-Asencio JM, Canca-Sanchez JC, et al. Instruments for assessing the risk of falls in acute hospitalized patients: a systematic review and meta-analysis. BMC Health Serv Res. 2013; 13:122.

20. Matarese M, Ivziku D, Bartolozzi F, Piredda M, De Marinis MG. Systematic review of fall risk screening tools for older patients in acute hospitals. J Adv Nurs. 2015;71:1198-1209.

21. Latt MD, Loh KF, Ge L, Hepworth A. The validity of three fall risk screening tools in an acute geriatric inpatient population. Australas J Ageing. Epub March 15, 2016.

22. Schaeffner ES, Ebert N, Delanaye P, et al. Two novel equations to estimate kidney function in persons aged 70 years or older. Ann Intern Med. 2012;157:471-481.

23. Lopes MB, Araújo LQ, Passos MT, et al. Estimation of glomerular filtration rate from serum creatinine and cystatin $\mathrm{C}$ in octogenarians and nonagenarians. BMC Nephrol. 2013;14:265.

24. Mathias S, Nayak US, Isaacs B. Balance in elderly patients: the "get-up and go" test. Arch Phys Med Rehabil. 1986;67:387-389.

25. Tinetti ME: Performance-oriented assessment of mobility problems in elderly patients. J Am Geriatr Soc. 1986;34:119-126.

26. Folstein MF, Folstein SE, McHugh PR. Mini-mental state: a practical method for grading the cognitive state of patients for the clinician. J Psychiatr Res. 1975;12:189-198.

27. Sheikh JI, Yesavage JA. Geriatric Depression Scale (GDS): recent evidence and development of a shorter version. Clin Gerontol. 1986;5: $165-173$.

28. Mahoney FI, Barthel DW. Functional evaluation: the Barthel Index. Md State Med J. 1965;14:56-61.

29. Lawton MP, Brody EM. Assessment of older people: self-maintaining and instrumental activities of daily living. Gerontologist. 1969;9: 179-186.

30. Inouye $\mathrm{SK}$, van Dyck $\mathrm{CH}$, Alessi $\mathrm{CA}$, et al. Clarifying confusion: the confusion assessment method. A new method for detection of delirium. Ann Intern Med. 1990;113:941-948.

31. McKhann GM, Knopman DS, Chertkow H, et al. The diagnosis of dementia due to Alzheimer's disease: recommendations from the National Institute on Aging-Alzheimer's Association workgroups on diagnostic guidelines for Alzheimer's disease. Alzheimers Dement. 2011;7: 263-269.

32. Joyce CR, Zutshi DW, Hrubes V, Mason RM. Comparison of fixed interval and visual analogue scales for rating chronic pain. Eur J Clin Pharmacol. 1975;8:415-420.

33. Hjermstad MJ, Fayers PM, Haugen DF, et al. Studies comparing numerical rating scales, verbal rating scales, and visual analogue scales for assessment of pain intensity in adults: a systematic literature review. J Pain Symptom Manage. 2011;41:1073-1093.

34. Wary B. Doloplus-2, a scale for pain measurement. Soins Gerontol. 2011;19:25-27.

35. Lefebvre-Chapiro S. The Doloplus-2 scale - evaluating pain in the elderly. Eur J Palliat Care. 2001;8:191-194.

36. National Institute for Health and Care Excellence. Falls. Assessment and prevention of falls in older people. Issued: June 2013. NICE guidance number guidance.nice.org.uk/CG161. Available from: www.nice.org. uk/guidance/CG161. Accessed March 6, 2016.

37. Figueiro MG, Plitnick B, Rea MS, Gras LZ, Rea MS. Lighting and perceptual cues: effects on gait measures of older adults at high and low risk for falls. BMC Geriatr. 2011;11:49.

38. Khachiyants N, Trinkle D, Son SJ, Kim KY. Sundown syndrome in persons with dementia: an update. Psychiatry Investig. 2011;8: $275-287$.

39. López-Soto PJ, Manfredini R, Smolensky MH, Rodríguez-Borrego MA. 24-hour pattern of falls in hospitalized and long-term care institutionalized elderly persons: a systematic review of the published literature. Chronobiol Int. 2015;32:548-556.

40. Coutinho ES1, Fletcher A, Bloch KV, Rodrigues LC. Risk factors for falls with severe fracture in elderly people living in a middle-income country: a case control study. BMC Geriatr. 2008;8:21. 
41. Bieniek J, Wilczyński K, Szewieczek J. Fried frailty phenotype assessment components as applied to geriatric inpatients. Clin Interv Aging. 2016;11:453-459.

42. Kojima G, Kendrick D, Skelton DA, Morris RW, Gawler S, Iliffe S. Frailty predicts short-term incidence of future falls among British community-dwelling older people: a prospective cohort study nested within a randomised controlled trial. BMC Geriatr. 2015;15:155.

43. Hubbard RE, Lang IA, Llewellyn DJ, Rockwood K. Frailty, body mass index, and abdominal obesity in older people. J Gerontol A Biol Sci Med Sci. 2010;65:377-381.

44. Sheehan KJ, O’Connell MD, Cunningham C, Crosby L, Kenny RA. The relationship between increased body mass index and frailty on falls in community dwelling older adults. BMC Geriatr. 2013;13:132.

45. Flaherty JH. Delirium. In: Sinclair AJ, Morley JE, Vellas B, editors. Pathy's Principles and Practive of Geriatric Medicine. Vol 2. 5th ed. Chichester, UK: Willey-Blackwell; 2012:837-850.

46. Inouye SK, Westendorp RGJ, Saczynski JS. Delirium in elderly people. Lancet. 2014;383:911-922.

47. Oliver D, Britton M, Seed P, Martin FC, Hopper AH. Development and evaluation of evidence based risk assessment tool (STRATIFY) to predict which elderly inpatients will fall: case-control and cohort studies. BMJ. 1997;315:1049-1053.
48. Hendrich AL, Bender PS, Nyhuis A. Validation of the Hendrich II fall risk model: a large concurrent case/control study of hospitalized patients. Appl Nurs Res. 2003;16:9-21.

49. Pendlebury ST, Lovett NG, Smith SC, et al. Observational, longitudinal study of delirium in consecutive unselected acute medical admissions: age-specific rates and associated factors, mortality and re-admission. BMJ Open. 2015;5:e007808.

50. Otremba I, Wilczyński K, Szewieczek J. Delirium in the geriatric unit: proton-pump inhibitors and other risk factors. Clin Interv Aging 2016;11:397-405.

51. Ambrose AF, Paul G, Hausdorff JM. Risk factors for falls among older adults: a review of the literature. Maturitas. 2013;75:51-61.

52. Fletcher PC, Hirdes JP. Restriction in activity associated with fear of falling among community-based seniors using home care services. Age Ageing. 2004;33:273-279.

53. Waters TM, Daniels MJ, Bazzoli GJ, et al. Effect of medicare's nonpayment for hospital-acquired conditions: lessons for future policy. JAMA Intern Med. 2015;175:347-354.
Clinical Interventions in Aging

\section{Publish your work in this journal}

Clinical Interventions in Aging is an international, peer-reviewed journal focusing on evidence-based reports on the value or lack thereof of treatments intended to prevent or delay the onset of maladaptive correlates of aging in human beings. This journal is indexed on PubMed Central, MedLine,

\section{Dovepress}

CAS, Scopus and the Elsevier Bibliographic databases. The manuscript management system is completely online and includes a very quick and fair peer-review system, which is all easy to use. Visit http://www.dovepress. $\mathrm{com} /$ testimonials.php to read real quotes from published authors. 